\title{
Evaluation of mutagenic potential of acetamiprid by dominant lethal test on Culex quinquefasciatus
}

\author{
M amta Bansal ${ }^{1 *}$ and A sha Chaudhry ${ }^{2}$ \\ ${ }^{1}$ Centre of Environment and Vocational Studies, Panjab University, Chandigarh-160014, INDIA \\ ${ }^{2}$ Mosquito Cytogenetics Unit, Department of Zoology, Panjab University, Chandigarh-160014, INDIA \\ *Corresponding author. E-mail: mamta_peehu@yahoo.in
}

\begin{abstract}
Acetamiprid, a member of the neonicotinoid insecticide family, is a new class of insecticide which has recently entered the market place. It is very selective and provides outstanding control of sucking pests such as aphids and whiteflies of major crops. In the present investigation, dominant lethal test (DLT) is adopted for the evaluation of the genotoxic effects of acetamiprid using Culex quinquefasciatus as an experimental model. In this experiment, the males hatched from larvae treated with $\mathrm{LD}_{40}$ were cross mated with normal females and the results were based on the number of hatched and unhatched eggs laid by these females. The statistical analysis of the results for $\mathrm{LD}_{40}$ treated groups gave the values of $37.526 \pm 3.886$ as against $5.23 \pm 0.77$ from the nontreated groups which indicated significant dominant lethality of $p<0.01$. These results indicated that exposure of pesticides even at small dose level proved deleterious to the genome of mosquito and its subsequent generation.
\end{abstract}

Keywords: Dominant lethality, Acetamiprid, Culex quinquefasciatus

\section{INTRODUCTION}

The neonicotinoids are the newest major group of insecticides, which includes acetamiprid, imidacloprid, clothianidin, dinotefuran, nitenpyram, thiacloprid, and thiamethoxam (Tomizawa and Casida, 2005). Neonicotinoids have proved to be ideal alternatives to organophosphates and carbamates (Elbert et al., 1998) with much lower rate of application as compared to traditionally used insecticides (Schmuck, 2001). In the present study, acetamiprid is selected which is used against sucking insects, such as aphids and whiteflies on leafy vegetables, cole crops, citrus, cotton, ornamentals, and fruiting vegetables. Mammals and humans are exposed to its residues during agricultural practice or when it enters the food chain. Once entered in the body it attacks on the central nervous system of insect by binding of acetylcholine, the major excitatory neurotransmitter in insects to the nAChRs, that further cause excitation and paralysis, followed by the death of the insect. Acetamiprid has relatively low acute and chronic toxicity in mammals with no evidence of carcinogenicity, neurotoxicity, mutagenicity and/or endoctrine disruption (USEPA, 2002). Data related to its toxicity is very scarce. But some of the recent studies conducted by Kocaman and Topaktas $(2007,2009)$ on human peripheral lymphocytes in culture showed various types of chromosomal aberrations and sister chromatid exchanges. In the last few years several toxicity testing procedures have been designed, modified and improved in such a way that they are acceptable to toxicologists (Lu, 1991; Anderson and Conning, 1993). In recent years, a number of in vivo and in vitro protocols have been successfully used to evaluate the genotoxic potential of suspect environmental mutagens (Amer and Ali, 1968; Gaulden and Liang, 1982; Jain and Sarbhoy, 1988). Among them, dominant lethal test (DLT) is one such in vivo procedure which is used for evaluating the mutagenic potential of pesticides on the progenies of the treated parents. It is based on the frequency of viable and nonviable embryos produced from crosses between treated males with untreated females in which dominant lethal effect is manifested in the form of embryonic deaths. Therefore, this test also helps to determine the sensitivity of the germ cells to the chemical mutagens (Manna and Sarkar, 1998).

In the present investigations, a mosquito Culex quinquefasciatus was considered an ideal test system as it has a high reproductive potential and only six as the diploid number of chromosomes, whereby abnormalities present in the germ cells can be easily detected along with visible phenotypic changes in the adults. These mosquitoes lay eggs in groups (egg rafts) in which it is convenient to observe all the eggs laid by an individual. In order to meet the present objectives the dominant lethality of acetamiprid was evaluated by at $\mathrm{LD}_{40}$ dose level. Although, this dose is considered sublethal yet it prove high enough to cause detectable effect. 


\section{MATERIALS AND METHODS}

Acetamiprid ((E)-N- [(6-chliro-3-pyridyl)]-N-cyano-Nmethyl acetamidine) is commonly sold in the form of white solid powder (Aventis Crop Sciences, U.S.A) under CAS no. 135410-20-7 and molecular formula $\mathrm{C}_{10} \mathrm{H}_{11} \mathrm{ClN}_{4}$ (Fig. 1) and molecular weight of 222.68. For the present study, $\mathrm{LD}_{40}$ was calculated by probit analysis and were found to be $8.9 \times 10^{-4} \mu 1 / \mathrm{ml}$ (Finney, 1971, Fig. 2).

The gravid females of Culex quinquefasciatus Say were collected from village inhabitation of a rivulet, $20 \mathrm{kms}$ East of Chandigarh. They were allowed to lay eggs in water filled petridishes placed in the breeding cages. The egg rafts obtained in this way were allowed to hatch and the larvae were reared on a protein rich diet consisting of a mixture of finely powdered dog biscuits and yeast powder in the ratio of 6: 4 respectively. A colony was raised under suitable conditions of temperature and humidity in mosquito rearing laboratory (Krishnan, 1964; Singh et al., 1975). Fixed number of freshly hatched healthy fourth instar larvae were treated with $\mathrm{LD}_{40}$ dose of the pesticide by rearing them in acetamiprid containing rearing medium for 24 hours after which they were transferred to pesticide free water and allowed to grow upto adult stages. Similarly, parallel controls of larvae were also reared upto adult stages and the freshly hatched adults of both the sexes were fed on $10 \%$ sucrose/

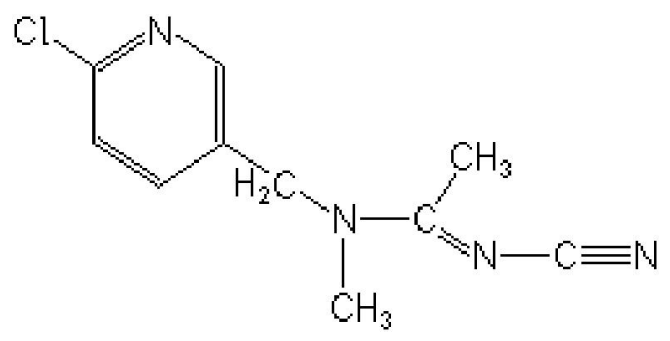

Fig. 1. Chemical structur e of acetamiprid.

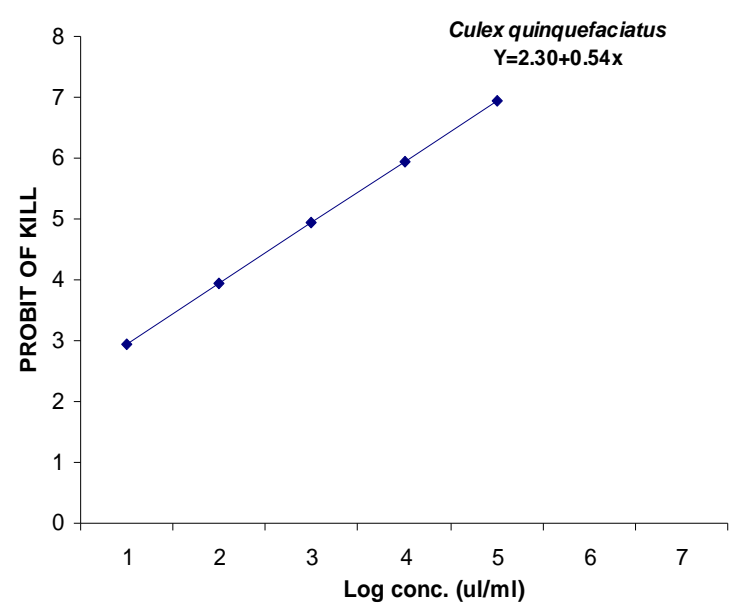

Fig. 2. Relationship between the probit of kill and $L D_{40}$ of acetamiprid showing the regression line represented by the equation $Y=a+b x$. glucose solution. The treated males were crossmated with nontreated females after which the females were provided with a blood meals by trapping a mice in a restrainer cage before keeping the same in the breeding cage (Muro and Goyer, 1969). After 4-5 days, females laid eggs which were allowed to hatch and after one week all the eggs were examined under suitable magnification of a dissecting microscope. The eggs with open opercula were considered as hatched while those with closed opercula (Figs. 3, 4) were taken as unhatched. The frequency of unhatched egg was taken as the criterion to evaluate the effects on the viability of embryos. Based on these figures the percentage frequency of induced lethality was calculated by applying the following formula.

Percentage frequency of unhatched eggs $=$

No. of unhatched eggs in an egg raft X 100 Total no. of eggs in an egg raft

Statistical analysis: The whole experiment was repeated five times and the statistical analysis was carried out by applying Student t- test using significance level of 0.01 .

\section{RESULTS AND DISCUSSION}

Assessment of dominant lethal mutations through crossing experiments is a widely accepted parameter for determining the genotoxicity of environmental mutagens (Suter, 1975; Manna and Sarkar, 1998). In the present set of experiments, the percentage frequency of lethal mutations which produced nonviable eggs is presented in Tables 1 and 2. Table 1 represents the percentage frequency of unhatched eggs of nontreated individuals of Culex quinquefasciatus, whereas Table 2 represents the percentage frequency of unhatched eggs of Culex quinquefasciatus treated with $\mathrm{LD}_{40}$ of pesticide.

Table 1. Percentage frequency of unhatched eggs in control stocks of $C x$. quinquefasciatus.

\begin{tabular}{lcccc}
$\begin{array}{l}\text { No. of } \\
\begin{array}{c}\text { Egg } \\
\text { raft }\end{array}\end{array}$ & $\begin{array}{c}\text { Total no. of } \\
\text { eggs in an } \\
\text { egg raft }\end{array}$ & $\begin{array}{c}\text { No. of } \\
\text { eggs } \\
\text { hatched }\end{array}$ & $\begin{array}{c}\text { No. of } \\
\text { eggs } \\
\text { unhatched }\end{array}$ & $\begin{array}{c}\% \text { frequency } \\
\text { of unhatched } \\
\text { eggs }\end{array}$ \\
\hline 1 & 112 & 104 & 8 & 7.14 \\
2 & 118 & 112 & 6 & 5.08 \\
3 & 103 & 96 & 7 & 6.8 \\
4 & 95 & 92 & 3 & 3.16 \\
5 & 100 & 96 & 4 & 4 \\
\hline
\end{tabular}

Table 2. Percentage frequency of unhatched eggs of $C X$. quinquefasciatus treated with $\mathrm{LD}_{40}$ of acetamiprid.

\begin{tabular}{lcccc}
\hline $\begin{array}{l}\text { No. of } \\
\text { egg raft }\end{array}$ & $\begin{array}{c}\text { Total no. of } \\
\text { eggs in an } \\
\text { egg raft }\end{array}$ & $\begin{array}{c}\text { No. of } \\
\text { eggs } \\
\text { hatched }\end{array}$ & $\begin{array}{c}\text { No. of } \\
\text { eggs } \\
\text { unhatched }\end{array}$ & $\begin{array}{c}\text { \% frequency } \\
\text { of unhatched } \\
\text { eggs }\end{array}$ \\
\hline 1 & 100 & 65 & 35 & 35.00 \\
2 & 92 & 47 & 45 & 48.49 \\
3 & 115 & 83 & 32 & 27.83 \\
4 & 107 & 60 & 47 & 43.93 \\
5 & 97 & 66 & 31 & 31.96 \\
\hline
\end{tabular}


Table 3. Statistical analysis of dominant lethality of $C x$. quinquefasciatus treated with $\mathrm{LD}_{40}$ of acetamiprid.

\begin{tabular}{lccccc}
\hline $\begin{array}{l}\text { Type of larval } \\
\text { stock }\end{array}$ & $\begin{array}{c}\text { No. of egg rafts } \\
\text { counted }\end{array}$ & $\begin{array}{c}\text { \% frequency of } \\
\text { unhatched eggs }\end{array}$ & $\begin{array}{c}\text { Standard } \\
\text { deviation }\end{array}$ & Standard error & ' $\mathrm{t}$ ' value \\
\hline Control & 5 & 5.236 & 1.727 & 0.7724 & 7.505 \\
Treated & 5 & 37.526 & 8.689 & 3.886 & d.f $=4$ \\
\hline
\end{tabular}

d.f. $=$ degree of freedom, $\mathrm{p}<0.01$

Accordingly, the average frequency of unhatched eggs was $37.44 \%$ as against $3.88 \%$ in the controls. The percentage frequency of dominant lethality was $37.52 \pm$ 3.88 as against $5.23 \pm 0.77$ in the controls. The t value was 7.50 at d.f. 4 which showed considerably significant value at $\mathrm{p}<0.01$ (Table 3, Figs. 3, 4, 5, 6). Most of the mutagens are known to have a damaging effect on the viability of the treated gametes and their chromosomes which ultimately reduces the normal production of viable embryos. This evidence was also provided by Brewen et al. (1975) who showed that the broken chromosomes due to the mutagenic action of chemical mutagen were eventually lost at anaphase, resulting in the death of the

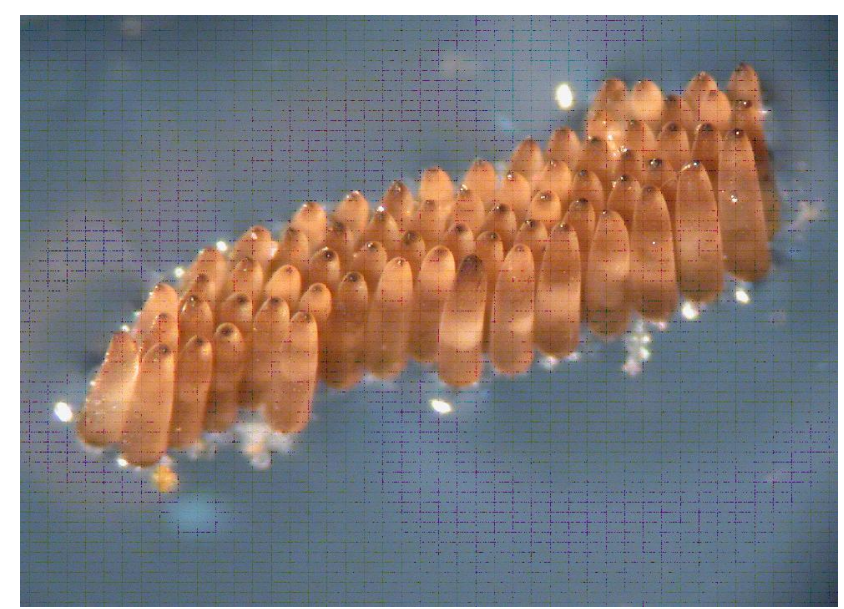

Fig. 3. Egg raft with closed opercula of nontreated $C x$. quinquefasciatus.

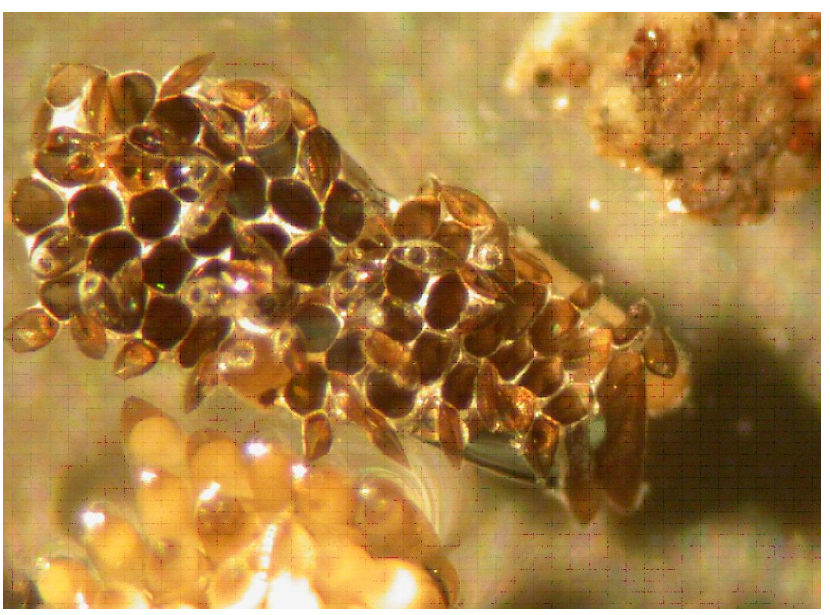

Fig. 4. Egg raft with open opercula of nontreated $C X$. quinquefasciatus. developing embryo. Bender et al. $(1973,1974)$ proposed a model by which chromosomal aberrations could be induced by a mutagen in the germ cells. Their studies strongly supported the view that the dominant lethality was the outcome of the loss of chromosomal material by way of deletions in the chromosomes of gametes. This was due to high frequency of damage to the male germ cell chromosomes which ultimately resulted in early embryonic deaths. Sharma et al. (1989) performed dominant lethal tests using $C x$. quinquefasciatus as an experimental insect in which the extent of dominant lethality was assessed by measuring the percentage frequency of hatched and unhatched eggs in both treated

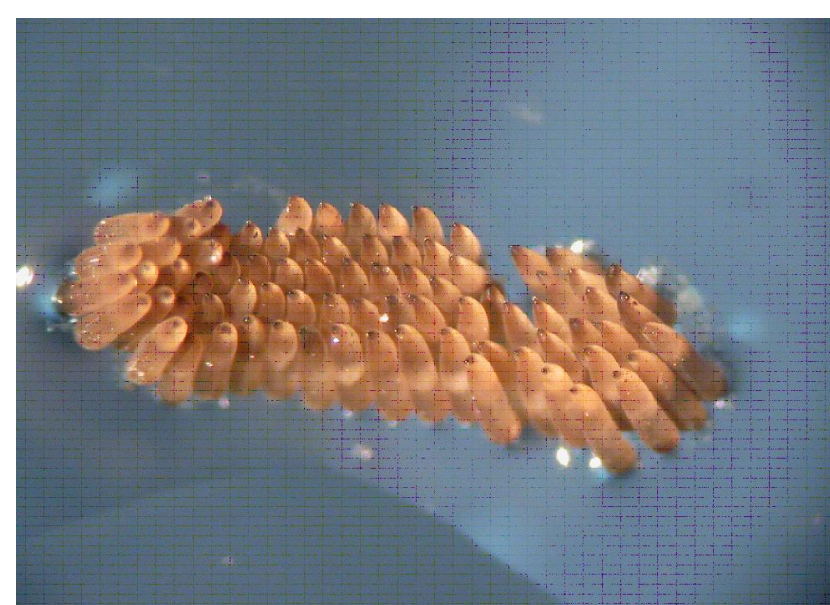

Fig. 5. Egg raft with closed opercula of treated CX. quinquefasciatus.

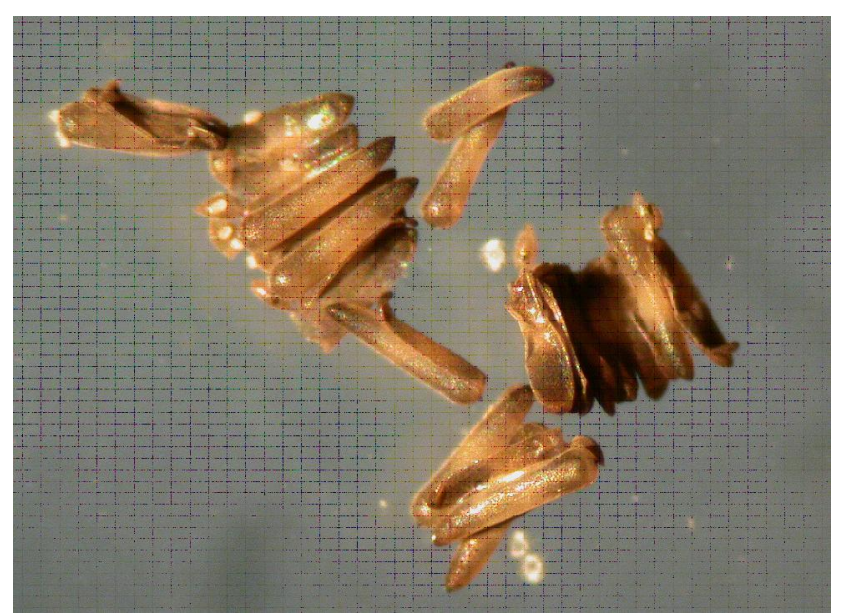

Fig. 6. Egg raft with open and closed opercula of treated CX. quinquefasciatus. 
and control stocks of mosquitoes. More recent, Chaudhry and her co- workers also performed similar experiments with improved protocols of cytogenetics to evaluate the genotoxicity of some pesticides such as chloropyrifos, imidacloprid, cypermethrin, carbaryl and monocrotophos $F_{1}$ generations after mating treated males with different sets of virgin females. The results showed the occurrence of significantly high level of dominant lethality (Chaudhry and Anand, 2004; Chaudhry et al., 2008; Chaudhry and Lovleen, 2008; Bhinder et al., 2009). Some of the recent reprints indicate that exposure to acetamiprid is related to induction of chromosomal aberrations and sister chromatid exchanges in human peripheral lymphocytes at almost all the concentrations and treatment times (Kocaman and Topaktas, 2007, 2009). To the contrary, the test carried out on lower animals like termites showed that even at low dose of $4.8 \mathrm{ppm}$ of acetamiprid, more than $90 \%$ individuals died within 120 hr of exposure (Mo et al., 2005). Related to such studies on the toxicity of acetamiprid, the larvae of mosquito Culex pipiens pallens were also exposed to pesticides, after which the results indicated that these larvae were highly sensitive to acetamiprid as their mortality rate was significantly high as compared to the normal nontreated stocks. The 1st instar larvae were the most susceptible to acetamiprid as compared to 4th instar larvae which were found to be more tolerant to the action of acetamiprid (Mo et al., 2008). According to El Hassani et al., (2008) and Yassine et al., (2009), field studies showed that acetamiprid was also found to affect the non-target species of insects like honeybees (Apis mellifera). When the toxicity of acetamiprid was compared with imidacloprid and thiamethoxam among the species of termites it was found that acetamiprid was more toxic than imidacloprid but less toxic than thiamethoxam (Rust and Saran, 2008).

In summation it may be added that dominant lethal test is an ideal parameter for evaluating the genotoxic potential of acetamiprid and other pesticides at different dose concentrations which prove harmful to the genomic contents of the test organism mosquito. The present study shows that genetic damage caused by such a lower dose of $\mathrm{LD}_{40}$ is so high which further proves the risk of acetamiprid at further higher doses. It also raises a point of caution that, the exposure directly acting pesticide could be deleterious to the genome of other living system including man.

\section{ACKNOWLEDGEMENTS}

The authors are grateful to Chairperson, Department of Zoology and Co-ordinator of Centre of Environment and Vocational Studies, Panjab University, Chandigarh for providing necessary facilities to carry out present research work. The authors are also thankful to the photographic section, Department of Biotechnology for providing necessary facilities to present the photographs.

\section{REFERENCES}

Amer, S. M. and Ali, E. M. (1968). Cytological effects of pesticides III: Meiotic effects of some phenols. Cytologia, 33: 21-33.

Anderson, D. and Conning, D. M. (1993). Experimental toxicology: The basic issue. The Royal Society of Chemistry. Cambridage. 405-440.

Bender, M. A., Bedford, J. S. and Mitchell, J. B. (1973). Mechanisms of chromosome aberration production II. Aberrations induced by 5- bromodeoxyuridine and visible light. M utat. Res., 20: 403- 416.

Bender, M. A., Griggs, H. G. and Bedford, J. S. (1974). Mechanisms of chromosome aberration production III. Chemicals and ionizing radiation. M utat. Res., 23: 187- 212.

Bhinder, P., Chaudhry, A. and Barna, B. (2009). rDNA ITS 2, polytene chromosomes and dominant lethal test based genotoxicity assessment oftwo pesticides using mosquito genome, Proc. International Conference on Entomology, Punjabi University, Patiala, Punjab.

Brewen, J. G., Payne, H. S., Jones, K. P. and Preston, R. J. (1975). Studies on chemically induced dominant lethality. The cytogenetic basis of MMS-induced dominant lethality in post meiotic-male germ cells. M utat. Res., 33: 239-250.

Chaudhry, A. and Anand, P. K. (2004). Assessment of dominant lethal effects of chlorpyrifos (CPF) using mosquito genetics. Poll. Res., 23(4): 767-771.

Chaudhry, A., Bhinder, P. and Kaur, R. (2008). r-DNA-ITS 1 $\& 2$ genes, polytene chromosomes and dominant lethal test based genotoxicity assessment of cypermethrin using mosquito genome, Proc. $2^{\text {rd }} \mathrm{Chandigarh}$ Science Congress, Panjab University, Chandigarh, $\mathrm{p}, 84$.

Chaudhry, A. and Lovleen (2008). Evaluation of mutagenic potential of Carbaryl by dominant lethal test on Culex quinquefasciatus. J. Cytol. G enet., 9: 37- 44.

Elbert, A., Nauen, R. and Leicht, W. (1998). Imidacloprid, a novel chloronicotinyl insecticide: biological activity and agricultural importance. In: I. Ishaaya and D. Degheele (Eds.), Insecticides with novel modes of action: Mechanism and application (pp 50-74), Springer Verlag, Berlin, Heidelberg.

El Hassani, A. K., Dacher, M., Gary, V., Lambin, M., Gauthier, M., and Armengaud, C. (2008). Effects of sublethal doses of acetamiprid and thiamethoxam on the behavior of the honeybee (A pis mellifera). Arch. Environ. Contam. Toxicol., 54: 653-661.

Finney, D. J. (1971). Probit Analysis. Cambridge Univ Press, Cambridge.

Gaulden, M. E. and Liang, J. C. (1982). Insect cells of testing clastogenic agents. In: T. C. Hsu (Ed.), Cytogenetic assays of Environmental Mutagens (pp 107-135), Allanheld: Osmum.

Jain, A. K. and Sarbhoy, R. K. (1988). Cytogenetical studies on the effects on some chlorinated pesticides III Concluding remarks. Cytologia, 53: 427- 436.

Kocaman, A. Y. and Topaktas, M. (2007). In vitro evaluation of the genotoxicity of acetamiprid in human peripheral blood lymphocytes. Environ. Mol. Mutagen, 48: 483-490.

Kocaman, A.Y. and Topaktas, M. (2009). The in vitro genotoxic 
effects of a commercial formulation of $\alpha$-cypermethrin in human peripheral blood lymphocytes. Environ. Mol. Mutagen, 50: 27-36.

Krishnan, K. S. (1964). A note on colonization of Culex. Bull. WId. HIth. O rg., 31: 455- 456.

Lu, F. C. (1991). Basic toxicology fundamentals: Target organs and risk assessment $\left(2^{\text {nd }}\right.$ ed $)$ Hemisphere Publishing Company, New York

Manna, G. K. and Sarkar, C. S. (1998). Mutagenic potential of the antifungal antibiotic grisefulvin to orally administered experimental mice and its follow- up in $\mathrm{F}_{1}$ and $\mathrm{F}_{2}$ generations. Perspective in Cytology and Genetics, AICCGpublic, Kalyani University, Kalyani, India. 383-393.

Mo, J., Pan, C., Zhang, S., He, H. and Cheng, J. (2005). Toxicity of acetamiprid to workers of Reticuliter mes flaviceps (Isoptera: Rhinotermitidae),Copotermes formosanus (Isoptera: Rhinotermnitidae) and 0 dontotermes formosanus (Isoptera: Termitidae). J. Pestic. Sci ., 30: 187-191.

Mo, J., Yang, T., Chenf, J. and Song, X (2008). Lethal and sublethal effects of acetamiprid on the larvae of Culex pipiens Pallens. Insect Science, 9 (3): 45- 49.

Muro, L. A. and Goyer, R. A. (1969). Chromosome damage in experimental lead poisoning. Arch Pathol., 87: 660-663.

Rust, M. K. and Saran, R. K. (2008). Toxicity, repellency, and effects of acetamiprid on western subterranean termite (Isoptera: Rhinotermitidae). J. Econ. Entomol., 101(4): 1360- 1366.
Schmuck, R. (2001). Ecotoxicological profile of the insecticide thiacloprid. Pflanzenschutz Nachr Bayer, 54:161-184.

Sharma, G. P., Chaudhry, A., Sobti, R. C., Dhar, M. and Ahluwalia, K. K.(1989). Effect of mitomycin- C on the genetics of Culex fatigans (Diptera: Culicidae). La Kromosoma.

Singh, K. R. P., Patterson, R. S., La Breque, G. C. and Razdan, R. K. (1975). Mass rearing of C ules pipiens fatigans. Weid J. Com. Dis., 731-753.

Suter, K. E. (1975). Studies on the dominant lethal and fertility effects of the heavy metal compounds methylemercuric hydroxide mercuric chloride and cadmium chloride in the male and female mice. M ut. Res., 30: 365-374.

Tomizawa, M. and Casida, J. E. (2005). Neonicotinoid insecticide toxicology: Mechanisms of selective action. Annu. Rev. Pharmacol. Toxicol., 45:247-268.

U.S. Environmental Protection Agency (USEPA). (2002). Name of chemical: acetamiprid. Reason for issuance: conditional registration.(www.epa.gov/opprd001/factsheets/ acetamiprid.pdf).

Yassine, A., Adessalam, K., El Hassini, Vincent, G., Catherine, A., Michel, L. and Monoque, G. (2009). Subchronic exposure of honeybees to sublethal doses of pesticides: effects on behavior. Environ. Toxicol.Chem., 28(1): 113122. 